Delft University of Technology

\title{
Effect of Bio-oil on Rheology and Chemistry of Organosolv Lignin-Modified Bitumen
}

Zhang, Y.; Liu, X.; Ren, S.; Jing, R.; Lin, P.; Apostolidis, P.; Erkens, S.; Wang, Xuancang; Scarpas, Athanasios

DOI

10.1061/(ASCE)MT.1943-5533.0004140

Publication date

2022

Document Version

Accepted author manuscript

Published in

Journal of Materials in Civil Engineering

\section{Citation (APA)}

Zhang, Y., Liu, X., Ren, S., Jing, R., Lin, P., Apostolidis, P., Erkens, S., Wang, X., \& Scarpas, A. (2022). Effect of Bio-oil on Rheology and Chemistry of Organosolv Lignin-Modified Bitumen. Journal of Materials in Civil Engineering, 34(4), 1-16. [04022009]. https://doi.org/10.1061/(ASCE)MT.1943-5533.0004140

\section{Important note}

To cite this publication, please use the final published version (if applicable).

Please check the document version above.

\section{Copyright}

Other than for strictly personal use, it is not permitted to download, forward or distribute the text or part of it, without the consent of the author(s) and/or copyright holder(s), unless the work is under an open content license such as Creative Commons.

Takedown policy

Please contact us and provide details if you believe this document breaches copyrights.

We will remove access to the work immediately and investigate your claim. 


\section{Effect of Bio-oil on Rheology and Chemistry of Organosolv Lignin}

\section{Modified Bitumen}

Yi Zhang

School of Highway, Chang'an University, 710064, Xi'an, Shaanxi Province, P.R. China

yizhang@chd.edu.cn

Section of Pavement Engineering, Faculty of Civil Engineering \& Geosciences, Delft University of Technology, Stevinweg 1, 2628 CN Delft, The Netherlands

Y.Zhang-24@tudelft.nl

Xueyan Liu

Section of Pavement Engineering, Faculty of Civil Engineering \& Geosciences, Delft University of Technology, Stevinweg 1, 2628 CN Delft, The Netherlands

x.liu@tudelft.nl

Shisong Ren, Corresponding author

Section of Pavement Engineering, Faculty of Civil Engineering \& Geosciences, Delft University of Technology, Stevinweg 1, 2628 CN Delft, The Netherlands

Shisong.Ren@tudelft.nl

Ruxin Jing

Section of Pavement Engineering, Faculty of Civil Engineering \& Geosciences, Delft University of Technology, Stevinweg 1, 2628 CN Delft, The Netherlands

r.jing@tudelft.nl

Peng Lin

Section of Pavement Engineering, Faculty of Civil Engineering \& Geosciences, Delft University of Technology, Stevinweg 1, 2628 CN Delft, The Netherlands

P.Lin-2@tudelft.nl

Panos Apostolidis

Section of Pavement Engineering, Faculty of Civil Engineering \& Geosciences, Delft University of Technology, Stevinweg 1, 2628 CN Delft, The Netherlands

p.apostolidis@tudelft.nl

\section{Sandra Erkens}

Section of Pavement Engineering, Faculty of Civil Engineering \& Geosciences, Delft University of Technology, Stevinweg 1, 2628 CN Delft, The Netherlands

S.M.J.G.Erkens@tudelft.nl

Xuancang Wang

School of Highway, Chang'an University, 710064, Xi'an, Shaanxi Province, P.R. China wxc2005@chd.edu.cn 
Tom Scarpas

School of Highway, Chang'an University, 710064, Xi'an, Shaanxi Province, P.R. China

A.Scarpas@tudelft.nl

Department of Civil Infrastructure and Environmental Engineering, Khalifa University of Science and Technology, Abu Dhabi, United Arab Emirates

Athanasios.skarpas@ku.ac.ae

\section{ABSTRACT}

Lignin, one of the most abundant natural polymers, has been extensively studied as an additive in bituminous binders. Even though the lignin improves the overall resistance against oxidative aging of bitumen, it could lead to high thermal cracking sensitivity. In this study, a bio-oil (i.e., rapeseed oil) is implemented in lignin modified bitumen to ameliorate characteristics, such as the resistance to fatigue and cracking. The long-term aging of bitumens formulated by different proportions of bio-oil was simulated by the pressure aging vessel method. Fourier Transform Infrared Spectroscopic (FTIR) results demonstrated lignin has a remarkable anti-aging effect, but adding bio-oil will slightly deteriorate the anti-aging effect. The Brookfield rotational viscometer showed that the addition of bio-oil was able to reduce the binder's viscosity observably, thereby improving the workability of bitumen. The frequency sweep tests revealed that lignin increased the stiffness and improved the thermal stability. Also, the multiple stress creep recovery tests corroborated that lignin significantly enhanced the rutting resistance of binders. The fatigue and thermal cracking properties of lignin modified binder could be strengthened by increasing bio-oil content which is confirmed from both linear amplitude sweep, Glover-Rowe parameter, and Bending Beam Rheometer tests. Moreover, the relaxation test results demonstrated that bio-oil decreased the residual stress ratio and relaxation time dramatically. Overall, this study has shown preliminary conclusions on the incorporating of bio-oil to enhance the medium-low temperature properties of lignin modified binders. In the meantime, bio-oil did not interfere with the improvement influence of lignin on the neat bitumen regarding high-temperature performance.

Keywords: lignin modified bitumen, bio-oil, chemistry, rheology, fatigue, thermal cracking

\section{Introduction}

Bitumen is a kind of petroleum-based constituent extracted from crude oil and the most 
extensively employed as the binder in pavement materials. Nowadays, Due to the uncertain supply and unrecoverability of crude oil, alternative materials are urgent to play a substituted role of petroleum originated bitumen. Recently, biomass has attracted a lot of attention as a modifier (Xu et al., 2017; Gao et al., 2020; Sundestrom et al., 1983; Perez et al., 2019) or replacement of bitumen (Gosselink et al., 2011; Van Vliet et al., 2016). The total amount of lignin that exists currently on Earth to be assessed at over 300 billion tons, as well as a growth of approximately 20 billion tons per year (Bruijnincx et al., 2016). Lignin is the second most abundant natural polymer which follows cellulose. Lignin can be detected as a co-product of waste wood production or byproducts from the pulp and paper industries. Therefore, the application of lignin in bitumen followed environmentally friendly and sustainable development and may create huge social and economic benefits.

Adding lignin can improve the performance of bitumen (Batista et al., 2018) and play a pivotal role as a partial replacement of bitumen (Arafat et al., 2019). Meanwhile, results have shown that lignin in bitumen could lead to enhanced thermal cracking sensitivity (Norgbey et al., 2020). The interaction mechanism between lignin and bitumen and the evaluation of characteristics of lignin modified bitumen at various temperatures have been previously studied (Zhang et al., 2019; Zhang et al., 2020). The most important indicator that limits the use of lignin in bitumen is the durability shortcoming at low temperatures, such as fatigue and thermal cracking sensitivity. To benefit from the use of lignin in bitumen, special attention should be given to improving the intermediate to low temperature performance of these binders.

Additionally, the utilization of bio-oil in bitumen has been extensively studied as liquid additive, performance extender, or partial replacement because of similar properties with petroleum bitumen (Dhasmana, 2015; Raouf, 2010). The addition of bio-oil in bitumen was reported that improve the low-temperature properties as well as the resistance to the fatigue cracking (Peralta, 2012; Raouf, 2010; Su et al., 2018). Metwally found the bio-oil improves the low temperature properties of bitumen (Metwally, 2010), unfortunately depresses the performance at high temperatures (Wen et al., 2012). Many researchers (Moghaddam et al., 2016; Mogawer et al., 2016) reported that bio-oil was able to act as rejuvenator and softener to improve the reclaimed asphalt pavement fatigue and thermal cracking resistance, while bio-oil modified bitumen showed high aging susceptibility (Girimath \& Singh, 2019). The bio-oil was 
capable of reducing the stiffness of the binder across all performance temperature ranges (MillsBeale et al., 2014; Lei et al., 2017). It was reported that bio-oil reduces the viscosity of bitumen and factory production temperature, saves fuel consumption and results in reduced gas and volatile emission (Ma et al., 2015; Fini et al., 2011). However, few studies have focused on the utilization of bio-oil in combination with lignin. If the bio-oil is proportionally added in the lignin modified bitumen, it may improve the overall temperature performances and increase the content of lignin.

Besides, the impact of polymer and bio-oil on rheology and oxidative aging of bitumen has attracted a lot of attention recently (Arafat, 2019; Moraes, 2014; Golalipour, 2013; Ruan et al., 2003), but most of these researches separate the bio-oil and polymers to evaluate their independent effects. The aging susceptibility of binders could be dramatically affected by the polymers, oils, as well as mineral fillers. Li et al. (2016) reported the effects of polymer and oil combination systems on susceptibility in terms of rheological and chemical performances. It has been shown that the interaction between polymer and oil significantly affects aging susceptibility. Xu et al. (2014) found that the polymer-modified bio-oil overall performs better than the original bio-oil and the dewatered bio-oil for the asphalt mixture performances. Haghshenas et al. (2021) researched the effect of recycling agents (three types of oil) blended with the antioxidant $(\mathrm{ZnDEC})$ on aged bitumen, it showed that the combination of recycling agent and antioxidant is effective. Lignin is a natural and complex polymer, the effect of combinations of lignin with bio-oil on the aging susceptibility, rheology, and chemistry is very important but lacks sufficient research.

\section{Objective}

In this study, a bio-oil has been used as a liquid additive in lignin modified bitumen to improve the material's low-intermediate temperature performance. DSR methods were used to assess the effects of bio-oil on the rheology of binders. The viscoelastic behavior of the binders was measured by the Frequency Sweep. High-temperature rutting characteristics were examined by MSCR tests. LAS tests were performed to measure the fatigue behavior of modified bitumen. Glover-Rowe Parameter and R-Value were derived to assess their overall cracking vulnerability of binders. Relaxation tests were conducted to evaluate relaxation properties, and BBR tests were used to evaluate the thermal cracking resistance as well. The 
results of virgin bitumen and lignin modified bitumen with and without bio-oil were compared to show the effect of lignin and bio-oil on bitumen. The key objectives of this research were to (i) assess the benefits of bio-oil in lignin modified bitumen at different temperatures, (ii) verify the effectiveness of bio-oil to improve the low-intermediate temperature performance of ligninmodified bitumen, and (iii) estimate the optimum dosage of bio-oil in the lignin modified bitumen based on performance testing.

\section{Materials and methods}

\subsection{Material Preparation}

In this research, a bitumen with a $70 / 100$ penetration and a softening point of $47.5^{\circ} \mathrm{C}$ was selected. The lignin $\left(1.3774 \mathrm{~g} / \mathrm{cm}^{3}\right)$ was nutbrown powder with a purity of over $88 \%$ which is extracted by the organosolv methods. The Braunauer-Emmett-Teller method (Braunauer et al., 1938; Apostolidis, 2015) was used to calculate the specific surface area (SSA) of powder by a surface measuring system (Dynamic Vapor Sorption). The SSA of fresh lignin powder was $147.0593 \mathrm{~m}^{2} / \mathrm{g}$. After aging, the SSA of lignin declined to $65.0475 \mathrm{~m}^{2} / \mathrm{g}$ and its density increased to $1.5031 \mathrm{~g} / \mathrm{cm}^{3}$.

The effect of different proportions of lignin in bitumen had been studied elsewhere (Zhang et al., 2019; Zhang et al., 2020). To restrain the scope of this study, the lignin content remained constant (30\% wt of bitumen) and different proportions of a bio-oil $(2,3$, and $4 \%$ wt of ligninmodified bitumen) were added to investigate properties at different temperatures. The bio-oil was a rapeseed oil with saturated, monounsaturated, and polyunsaturated fatty acids. The high shear mixer was employed to mix the modified binders and bio-oil, at $163^{\circ} \mathrm{C}, 3000 \mathrm{rpm}$, and for a half-hour.

The long-term aging of binders was performed with the PAV device according to ASTM D 6521-19. The PAV aging program was conducted after TFOT conditioning at $163^{\circ} \mathrm{C}$ and 5 hours for short-term aging based on ASTM D 1754-09. Then the samples were put in the PAV unit at $100^{\circ} \mathrm{C}, 2.1 \mathrm{MPa}$ for 20 hours. The primary performance parameters of studied materials were displayed in Table 1.

\subsection{Chemical Characterization}

The FTIR tests were the most commonly used method to trace the chemical functional groups in components. Different functional groups had different absorption spectrums, and 
different wavenumbers represented various typical chemical bands. The attenuated total reflectance (ATR) FTIR was used in this study to acquire the spectral data of different components. The wavenumber range and resolution of the device were 4000 to $600 \mathrm{~cm}^{-1}$ and 4 $\mathrm{cm}^{-1}$. Nine replicates per material were analyzed.

The carbonyl $\left(\mathrm{C}=\mathrm{O}\right.$, around $\left.1700 \mathrm{~cm}^{-1}\right)$ and sulfoxide $\left(\mathrm{S}=\mathrm{O}\right.$, around $\left.1030 \mathrm{~cm}^{-1}\right)$ indexes are conventional aging indices of bitumen. The lignin has the effect of anti-aging and could play the role of oxidant inhibiter in bitumen. The anti-aging effect of binders was evaluated by these two aging indexes which were according to the concentration of carbonyl and sulfoxide groups. The normalization of the Aging Index (AI) as follows:

$$
\begin{gathered}
A I_{C=O}=\frac{A_{C=O}}{\sum A} \\
A I_{S=O}=\frac{A_{S=O}}{\sum A} \\
\Delta A I=A I_{\text {Aged }}-A I_{\text {Fresh }}
\end{gathered}
$$

Where $\mathrm{A}_{\mathrm{C}=\mathrm{O}}$ and $\mathrm{A}_{\mathrm{S}=\mathrm{O}}$ represent the integral areas of carbonyl and sulfoxide groups, $\sum \mathrm{A}$ implies the sum of the integral areas of nine chosen representative and typical chemical functional group peaks (Zhang et al., 2019; Zhang et al., 2020) in the wavenumber range from 3000 to $700 \mathrm{~cm}^{-1}$ as summarized in Table 2 (Haghshenas et al., 2020; Lamontagne et al., 2001; Jing, 2019).

\subsection{Brookfield viscosity}

Low viscosity means better workability, the binder could be better mixed with the aggregate and cover the aggregate uniformly. It is expected the bio-oil could result in a decline in viscosity at different temperatures. The viscosity of lignin modified bitumen binder without and with different dosage bio-oil was tested by Brookfield rotational viscometer (AMETEK Brookfield DV2T) following the standard ASTM D 4402. From 75 to $165^{\circ} \mathrm{C}$, the viscosity of binders was measured. The temperature range included the temperature of the entire transportation, mixing, construction, and compaction. The spindle was Brookfield SC4-27 Thermosel Spindle and had a stainless-steel sample chamber with a sample volume of $10.4 \mathrm{~mL}$, rotational speed was 12 , and $20 \mathrm{rpm}$. The viscosity of binders at $135{ }^{\circ} \mathrm{C}$ and $20 \mathrm{rpm}$ was compared according to the specification (ASTM 6373-16) to ensure whether it is less than 3 
$\mathrm{Pa} \cdot \mathrm{s}$. Three replicates per sample were analyzed.

\subsection{Frequency Sweep}

The complex shear modulus $\left(G^{*}\right)$ and phase angle $(\delta)$ of bitumen were tested by a DSR in accordance with AASHTO T 315-19. The rheological behavior and performance of binders at both unaged and aged conditions were measured at various temperatures and frequencies. The configuration geometry of the testing parallel plate was $2 \mathrm{~mm}$ gap and $8 \mathrm{~mm}$ in diameter, the testing temperature range was -5 to $30^{\circ} \mathrm{C}$. The configuration of the $25 \mathrm{~mm}$ diameter and $1 \mathrm{~mm}$ gap was subjected to the elevated temperature, 30 to $60^{\circ} \mathrm{C}$. The frequency was performed from 100 to $0.1 \mathrm{rad} / \mathrm{s}$. The $20^{\circ} \mathrm{C}$ was the reference temperature, then the master curves of $G^{*}$ and $\delta$ were constructed by the sigmoidal model. The impact of aging and the different content of biooil were illustrated by the master curves. To obtain stable results, three replications of each binder were tested. Moreover, the rutting and fatigue factors of binders, $\mathrm{G}^{*} / \sin \delta$ and $\mathrm{G}^{*} \sin \delta$, were calculated to assess the properties and resistances.

\subsection{Multiple Stress Creep Recovery Test}

The MSCR tests were used to measure the elastic response and stress dependence of the binder under representative stress levels and temperatures (ASTM D 7405-15). The binders were tested by a load for $1 \mathrm{~s}$ and recovered for $9 \mathrm{~s}$ in every cycle. 20 cycles were applied first at $100 \mathrm{~Pa}$ and then 10 cycles under the $3200 \mathrm{~Pa}$ stress level. The first 10 cycles under $100 \mathrm{~Pa}$ were performed for the preconditioning of binders. The testing temperature was from 52 to $70^{\circ} \mathrm{C}$ with a $6{ }^{\circ} \mathrm{C}$ increment. The recoverability to the initial mechanical condition is characterized by the $\mathrm{R} \%$, while the $\mathrm{J}_{\mathrm{nr}}$ implies the residual strain after the cycle.

\subsection{Linear Amplitude Sweep Test}

The cyclic load with strain amplitudes increasing linearly was applied in the LAS test to evaluate the fatigue performance of bitumen (Hintz et al., 2013). The testing plates with a 2 $\mathrm{mm}$ gap and $8 \mathrm{~mm}$ diameter were used in LAS tests according to AASHTO TP 101-14. The LAS test was programmed as follows: the first step was the frequency sweep to evaluate the rheological properties of bitumen. The test was applied an oscillatory shear load of $0.1 \%$ strain at 12 typical frequencies from 0.2 to $30 \mathrm{~Hz}$. The studied samples were performed on the strain sweep at $10 \mathrm{~Hz}$ in the second step. Binder is prone to cracking failure at low temperatures than high temperatures under cyclic loading (Anderson et al., 2001). At a selected temperature of 
$20^{\circ} \mathrm{C}$, continuous oscillatory cycles with strain increasing from $0 \%$ to $30 \%$ were employed to accelerate the fatigue damage.

3.7. Determination of Glover-Rowe Parameter and R-value

The cracking vulnerability of asphalt materials was assessed by the performance indicator performed by the Glover-Rowe (G-R) parameter test and depicted in black space diagrams (BSD) (Airey et al., 2002; Mensching et al., 2015; King et al., 2012). The G-R parameter of binders was tested to evaluate the damage at $15^{\circ} \mathrm{C}$, and the test frequency was $0.005 \mathrm{rad} / \mathrm{s}$. The damage curves in the BSD represent the beginning of cracking and significant cracking as follows:

$$
G R=G^{*}(\omega) \times\left(\frac{\cos ^{2} \delta}{\sin \delta}\right)
$$

where $\mathrm{G}^{*}(\omega)$ is the complex shear modulus at frequency $\omega(\mathrm{rad} / \mathrm{s}), \delta$ is the phase angle $\left(^{\circ}\right)$, and $G R$ is the Glover-Rowe Parameter, which is 180 and $600 \mathrm{kPa}$ in this study (Rowe, 2016; Osmari et al., 2019). These two failure curves formed the damage zone. In addition, the BSD was divided into different crack-sensitive zones by the R-Value as follows:

$$
R=\frac{\log 2 \times \log \frac{G^{*}(\omega)}{G_{g}}}{\log \left(1-\frac{\delta}{90}\right)}
$$

where $R$ is the R-Value which is 1,2 , and 3 here, $G_{g}$ is the glassy modulus assumed to be $10^{9}$ $\mathrm{Pa}$. The R-Value is an important parameter to demonstrate the potential damage (Xu et al., 2021).

\subsection{Relaxation Test}

The ability of binders to release stress after an invariable strain was determined by the stress relaxation tests. The configuration geometry of testing parallel plate was $2 \mathrm{~mm}$ in gap and $8 \mathrm{~mm}$ in diameter was performed in DSR. The test was under strain controlled mode and the temperature was $0^{\circ} \mathrm{C}$. The experiment was designed in two parts, the first part was the strain rose from 0 to $1 \%$ in $0.1 \mathrm{~s}$, the second part was to keep the constant $1 \%$ shear strain in a relaxation time of $100 \mathrm{~s}$ (Jing, 2019; Kataware et al., 2012).

\subsection{Bending Beam Rheometer Test}

To better evaluate the low temperature properties, thermal cracking and relaxation, of bitumen, the stiffness modulus (s) and creep rate (m) were measured by the Bending Beam 
Rheometer (BBR) in accordance with AASHTO T 313-09. The Pressure Aging Vessel (PAV) aged bitumen was poured into the standard aluminum mold, then the demolded test sample beam $6.35 \mathrm{~mm}$ thick by $12.7 \mathrm{~mm}$ wide by $127 \mathrm{~mm}$ long was conducted at $-6,-12$, and -18 under seating load $980 \pm 50 \mathrm{mN}$. The data acquisition system of the rheometer recorded the load and displacement at the loading time of $0,0.5,8,15,30,60,120,240 \mathrm{~s}$ automatically.

\section{Results and discussion}

\subsection{Chemical Characterization}

FTIR spectra and chemical functional group changes of different lignin-bitumen and lignin-oil-bitumen systems were shown in Fig.1 (a) and (b). Some chemical functional groups of the lignin modified binder could be traced in neat asphalt and lignin modifier. After adding bio-oil, the peaks of the lignin-bitumen system were changed gradually. No new chemical functional group was detected in the mixing of lignin, virgin bitumen, and oil. It shows that the mixing does not produce a new chemical composition, no chemical reaction occurs, or the chemical reaction is very insignificant and could be ignored.

To better explore the aging state, the aging indices were calculated based on FTIR spectra according to the formula listed in the methodology. The carbonyl and sulfoxide indexes for lignin modified bitumen with different proportions of bio-oil before and after aging were depicted in Fig.2. Before aging, it revealed that the virgin bitumen has only negligible carbonyl and a small amount of sulfoxide. Both lignin and bio-oil were very complex organic substances. It was observed from the spectrum that lignin and bio-oil themselves contain carbonyl and sulfoxide. In particular, bio-oil had a very distinct peak near $1750 \mathrm{~cm}^{-1}$, which was a carbonoxygen $(\mathrm{C}=\mathrm{O})$ bond in fatty acid. Therefore, the addition of lignin increased the two kinds of aging functional groups. As the content of bio-oil gradually increased, the carbonyl group increased while the sulfoxide remained unchanged or even slightly decreased. Bio-oil only contained limited sulfoxide functional groups, so the addition of bio-oil slightly diluted the sulfoxide.

After aging, all aging indices increased. It shows that a chemical reaction occurred during the aging process to produce new carbonyl and sulfoxide groups. By comparing the results of Bref and BL30, it can be seen that lignin did decline the generation of aging functional groups. Carbonyl and sulfoxide indexes for fresh binder increased from 0.001 and 0.010 to 0.013 and 
0.020, separately. Regarding BL30, the aging indexes rise from 0.018 and 0.019 to 0.027 and 0.021. However, bio-oil had a different impact on aging. Regardless of bio-oil dosage, it greatly inhibited the production of sulfoxide functional groups. But more new carbonyl functional groups were generated under the aging procedure as the bio-oil content increasing. In addition, the Combined Aging Index (CAI) was applied to explore the volume average proportion of oxidized substances in Fig.3.

The Combined Aging Index was added by carbonyl index and sulfoxide index and displayed in the green part of the figure. The yellow part of the figure illustrated the increase in CAI after the aging process. The Increased Combined Aging Index of lignin modified bitumen (BL30) was 0.011 and the lowest. It shows that lignin had a strong inhibitory effect on the generation of aging functional groups. Bio-oil slightly weakened this inhibitory effect. The Increased Combined Aging index of lignin-modified asphalt containing 2\% and 3\% of bio-oil is 0.016 and 0.018 , respectively, and that of virgin bitumen (Bref) is 0.021 . The anti-aging effect of lignin-modified bitumen with $2 \%$ and $3 \%$ bio-oil was better than neat bitumen. Therefore, in order to obtain better anti-aging performance and produce fewer functional groups during the aging process, $2 \%$ and $3 \%$ were recommended here.

\subsection{Brookfield viscosity}

The viscosity value of different lignin-oil-bitumen systems from 75 to $165^{\circ} \mathrm{C}$ at 12 and $20 \mathrm{rpm}$ are illustrated in Fig.4. It revealed that the tested temperature and rotational speed of the spindle are the most important factors affecting viscosity. The viscosity decreased significantly with the increase in temperature and speed. It shows that the bitumen binder shows higher fluidity under high temperature and speed conditions. When the temperature exceeded $135^{\circ} \mathrm{C}\left(145 \sim 165^{\circ} \mathrm{C}\right)$, the viscosity of all studied samples was very close, and the influence of various factors on the binder can be ignored.

From Fig.4, adding lignin dramatically enhanced the viscosity value of bitumen by comparing the sample Bref and BL30. The viscosity of neat bitumen and lignin modified bitumen without bio-oil was found to be 0.633 and $1.133 \mathrm{~Pa} \cdot \mathrm{s}$ at $135{ }^{\circ} \mathrm{C}$. Although lignin observably increased viscosity, the viscosity values of the neat binder, as well as lignin modified bitumen, were both lower than $3 \mathrm{~Pa} \cdot \mathrm{s}$. The increase of bio-oil dosage gradually declined the viscosity. For example, at $135{ }^{\circ} \mathrm{C}$ and $20 \mathrm{rpm}$, the addition of 2,3 , and $4 \%$ bio-oil decreased 
the viscosity of BL30 by $22.8,33.8$, and $41.2 \%$, respectively. From the analysis of the entire temperature range, adding $3 \%$ bio-oil made the viscosity very close, and the $4 \%$ dosage was even better than the neat bitumen. Therefore, bio-oil can eliminate the negative impact of the addition of lignin on the increase in bitumen viscosity. The bio-oil contains a great amount of unsaturated fatty acids, which is similar to the light oil component of bitumen. The addition of bio-oil can soften the binder and increase its fluidity. Furthermore, it can improve its viscosity and workability. Even the temperature required for the production of modified asphalt can be appropriately reduced. To obtain better workability, higher fluidity, and eliminate the influence of lignin, 3 and $4 \%$ content of bio-oil was recommended.

\subsection{Master curve parameters}

The complex shear modulus and phase angle were both tested by using the frequency sweep method with temperature vary from -5 to $60^{\circ} \mathrm{C}$. The fitted master curves with the sigmoidal model were illustrated in Fig.5. The $G^{*}$ and $\delta$ were the y axis coordinates, and the frequency was the $\mathrm{x}$ axis coordinates. Generally, the binder with a higher modulus showed high deformation resistance, and a lower phase angle value represents a more elastic binder. The modulus increased with increasing frequency, and conversely, the phase angle decreased with increasing frequency. The stiffness for all bitumen samples was very similar when testing frequency reached a certain high level. The lower the frequency, the greater the difference in properties.

The aging affects the binder performance dramatically, and the modulus of the aged bitumen was much higher than that of the fresh ones. Also, the phase angle value for aged binders was smaller than the fresh ones. The lignin increased the stiffness and reduced the phase angle of bitumen, respectively. Concerning the fresh and aged conditions, consistent results were obtained by comparing the results of Bref and BL30. It shows that both the aging process and the addition of lignin make the binders stiffer. Although the increased modulus improved the temperature stability as well as the deformation resistance, it also increased the cracking thermal sensitivity of binders at low temperatures, which may be prone to brittle fracture. With the bio-oil dosage in modified binders increasing, the complex modulus master curve had a gradual downward trend, while the phase angle curve tended to move up. This trend was more obvious at high bio-oil proportions in binders. 
The rutting parameter and fatigue parameter were estimated by the temperature sweep test conducted from -5 to $60^{\circ} \mathrm{C}$, then the factors were non-linearly fitted in Fig.6, and the formulas and correlations were listed in Table 3. A linear relationship between testing temperature and rutting parameter as well as fatigue parameters in the logarithmic coordinates were observed. The rutting and fatigue parameters decreased significantly with the increase in temperature. Higher temperature, weaker resistance to rutting, and improved fatigue cracking resistance. Further, it was shown that aging makes the material stiffer, the material exhibits an enhancement ability to resist rutting distress but tends to crack easily because of its higher fatigue factor. By comparing Bref and BL30, the increase of rutting and fatigue parameters was observed due to the addition of lignin. Lignin can dramatically enhance the rutting resistance of bitumen, while has a negative influence on fatigue performance. The chemical composition of bio-oil itself is very close to that of the light oil component of bitumen. The addition of bio-oil can soften the binder, increase fluidity and reduce viscosity. This can make the bitumen less prone to fatigue cracks and reduce the propagation of fatigue cracks. Thus, the fatigue failure life and cycle under repeated loads are increased. Therefore, bio-oil ameliorated the fatigue performance, the factors declined with the increment of bio-oil in modified bitumen.

The fitting functions of the rutting and fatigue parameters were analyzed and shown in Table 3, the slope value of functions in the logarithmic coordinates indicates the material's sensitivity to temperature. The performance of binders with larger slopes would be more sensitive to the same temperature change. The higher temperature sensitivity meant the faster the rutting and fatigue parameters decreased with the temperature increase. Adding the lignin modifier (BL30) decreased the slope values of the functions, the temperature sensitivity, of bitumen compared with neat bitumen (Bref). It showed that lignin modified bitumen less dependent on temperature variation and lignin enhancing the thermal stability of binder. In addition, the slope increased slightly as the bio-oil content increasing.

\subsection{Multiple Stress Creep Recovery (MSCR)}

The MSCR characterization method was performed with representative stress levels at the temperature varies from 52 to $70^{\circ} \mathrm{C}$ with a $6{ }^{\circ} \mathrm{C}$ increment. The representative $64^{\circ} \mathrm{C}$ MSCR test load curves of samples are illustrated in Fig.7.

The stress level had an important influence on the shear strain, the strain of all studied 
binders increased significantly with the stress increase from 0.1 to $3.2 \mathrm{kPa}$. It revealed that binders were more likely to deform due to greater stress levels, it was also the reason why heavy vehicle load easily causes deformation of road materials (Airey et al., 2002). The shear strain gradually increased with repeated loads, repeated and continuous vehicle loads were more likely to cause strain accumulation. The shear strain of binders declined dramatically with the aging because the binders became stiffer. By comparing the neat binder with lignin modified bitumen (Bref and BL30), the addition of lignin descended the strain signally regardless of both unaged and aged binders. In other words, the lignin notably improves the resistance to the deformation of bitumen. Bio-oil had the opposite effect, as the content of bio-oil increasing, the strain gradually increased. The addition of $2 \%$ of bio-oil still had improved resistance to deformation. The ability to resist the deformation of lignin modified bitumen mixed with 3\% bio-oil was almost the same as neat bitumen, the load curves of the two binders overlapped each other.

The recovery and non-recovery performance were represented by the $R$ and $J_{n r}$ parameters, which were measured by the MSCR test. The recovery percentage decreased with increasing stress levels, while non-coverable compliance increased. The corresponding results for fresh and PAV aged binders were plotted in Fig.8. Aging was also a very important effect since the improvement of recovery percentage, as well as the deterioration of non-coverable compliance, were significant as bitumen binder aging. The higher the recovery percentage is, the more elastic the material is. While when the non-recoverable compliance is lower, the material is stiffer and more rigid. Recovery percentage increased and non-recoverable compliance decreased with increasing temperature. The binder exhibited more viscous and more prone to deform at high temperatures.

The influence of lignin content was obtained by comparing the results of Bref and BL30. A significant difference in the recovery ability of the bitumen was shown. The $\mathrm{R} \%$ value increased, while the Jnr parameter reduced, respectively, both at the fresh and aged conditions due to the incorporation of the lignin modifier. The lignin made the binder stiffer and significantly enhanced the recoverability. From a perspective of the high temperature of performance, adding lignin improves the mechanical recoverability of bitumen samples and enhances the overall rutting resistance. 
Bio-oil exhibited an adverse impact on the stress-recovery ability by comparing different

bio-oil content binders. The recovery percentage deteriorated because of the increase of bio-oil dosage, while the non-recoverable compliance increased gradually. Bio-oil reduced the hardness, making the material softer and more prone to plastic deformation. Therefore, bio-oil showed a negative influence regarding the high temperature properties. While comparing with the result of Bref, the high-temperature performance of the lignin modified bitumen with 2 or $3 \%$ bio-oil modifier was close to and even better than neat bitumen, only $4 \%$ bio-oil was worse than that of neat bitumen. Therefore, in consideration of not reducing the high-temperature performance of bitumen binders, 2 and $3 \%$ dosage was recommended here.

\subsection{Linear Amplitude Sweep (LAS)}

The LAS method was used to measure the fatigue resistance and behavior for lignin modified bitumen and the change curves of stress versus strain were shown in Fig.9. The stress increased first and then decreased with the strain, the first part could be regarded as a linear increase. The maximum stress and the corresponding strain value varied with different samples and aging conditions. With aging, the material became stiffer, the maximum stress increased, while the related strain value became lower. The addition of lignin increased the maximum stress, on the contrary, the maximum stress gradually reduced as the bio-oil dosage increasing. The order for the strain at maximum stress from low to high was BL30, Bref, BL30+2\%, 3\%, and $4 \%$ oil. It shows that the binder reached maximum stress faster as a result of lignin. While the binder became softer with the bio-oil, the binder required more strain to get the maximum stress both in fresh and aged conditions.

The failure cycles of various binders at representatives applied shear strain values, 2.5 and $5.0 \%$, were illustrated in Fig.10. The remarkable decrease in fatigue life was related to the increasing strain level. Fatigue life deteriorated after the addition of the lignin modifier regardless of the strain levels $(2.5 \& 5.0 \%)$ by comparing the samples Bref and BL30. The fatigue life of the BL30 was 24 and $23 \%$ of the Bref, under the applied strain level 2.5 and $5.0 \%$, respectively. Lignin led to stiffer binders, and binders increased the capacity of deformation resistance. However, it tends to brittle fracture easily, which has a considerable effect on the medium-low temperature properties, an observation consistent with previous studies (Xu et al., 2017; Gao et al., 2020). Even if lignin and bitumen were mixed uniformly, 
vulnerable interfaces between these two materials still exist, resulting in more susceptibility to damage under accumulated loads.

To reduce the embrittlement effect of lignin on bitumen and damage to fatigue performance, bio-oil was added in binders. The fatigue life of lignin modified binders gradually increased to 42,55 , and $68 \%$ of the virgin bitumen at the low strain level, while increased to 51,66 , and $90 \%$ at the high strain level with the increasing of bio-oil. The improvement after aging was more obvious, but it was still lower than the neat bitumen. Bio-oil could make the material softer, significantly reducing the fatigue damage sensitivity of binders. To improve fatigue life, content 3 and $4 \%$ of bio-oil were recommended.

\subsection{Glover-Rowe Parameter and R-Value Test}

The failure curve, the blue line represented the onset of cracking, and surface cracking was observed and represented by the red line. The relative value of the G-R parameters was 180 and $600 \mathrm{kPa}$, respectively. These two failure curves provided the damage zone in black space diagrams as shown in Fig.11. The diagram was further divided into different crack-sensitive regions on basis of the R-value. A larger R-value refers to the material more likely to crack. The location in black space diagrams evaluated the cracking vulnerability of materials. The round dots represented the fresh state of binders, and the triangular dots represented the state after the PAV aging.

The fresh binders were in a safe zone. After aging, all binders were closer to the failure curve and the R-values increased with aging, revealing binders prone to crack. Specifically, the aged bitumen (Bref) was near the blue line (onset of cracking), while the aged modified bitumen with a lignin content of 30\% (BL30) was near the red line (serious cracks) but still below the line. It shows that adding lignin improves the vulnerability of cracking and reduces cracking resistance ability. The fresh state of Bref, BL30 and BL30+2\% Oil was in the zone between $\mathrm{R}=1$ and $\mathrm{R}=2$, the aged samples were located in the zone between $\mathrm{R}=2$ and $\mathrm{R}=3$. However, the R-value of lignin modified bitumen with 3 and 4\% of bio-oil, both in unaged and aged condition, position in the region between $\mathrm{R}=1$ and $\mathrm{R}=2$ all the time, as such less cracking potential than Bref and BL30. The improvement effect was significant after adding bio-oil, it softened the bitumen and cracks were more difficult to occur. In addition, bio-oil significantly improves the properties after aging, all aged samples with bio-oil were farther away from the damage zone, 
indicating the anti-aging effect of bio-oil in binders. Due to less cracking potential, 3 and $4 \%$ dosage were recommended here.

\subsection{Relaxation Test}

The linear correlation between shear stress and the relaxation time of samples in the relaxation period in the double-logarithmic coordinates was depicted in Fig.12. The slope of the curve relaxation period characterizes the relaxation ability. More stress could be released within a certain relaxation time shows better relaxation performance. The maximum stress of all binders increased after aging, but the increment was not obvious. After aging, the slope became smaller and flatter. It shows that the residual shear stress increased at a certain relaxation time due to relaxation modulus increasing with aging, the relaxation ability decreased. Although the addition of lignin increases the maximum stress a little, it also caused stiffening of binder, the slope decreased a little, the residual stress at the same relaxation time increased. However, as the bio-oil content increasing gradually, the slope rose and the overall relaxation performance improved.

The ratio of residual and initial shear stresses of samples before and after aging was depicted in Fig.13 (a). This indicator represented the residual stress at the endpoint during the relaxation test. The larger the ratio of residual and initial shear stresses, the more residual stress, the worse the recoverability and relaxation property. The fresh binders have shown better elasticity and recoverability than the aged ones with a lower ratio, properties deteriorate with aging. The residual stress of the aged binders was more than the fresh after one load. Then under repeated loading, the real traffic vehicle loads, the more residual accumulated stress would not be released and recovered. The addition of lignin increased the stress ratio both in fresh and aged states by comparing Bref and BL30. It shows that lignin is detrimental to relaxation properties. As the bio-oil was added proportionally, this damaging effect was eliminated. The ratio of lignin modified bitumen with bio-oil was even smaller than that of the neat binder. In addition to the ratio, the speed and time of relaxation also needed to be analyzed. The relaxation times of studied binders when the shear stress was declined to a certain level were depicted in Fig.13 (b).

The index represented the time that the initial shear stress dropped from 100 to 50 and $25 \%$, respectively. The longer it took for the stress to decrease to a certain stress level, the worse 
the recoverability and relaxation performance. The studied bitumen samples with more relaxation times revealed more vulnerable to the accumulated stress (Anderson et al., 2001). The relaxation time should be short to avoid the possibility of stress accumulation in the road due to the continuous vehicle load. As the stress does not release timely, the road would accumulate more stress because of the next traffic load. The relaxation time of all samples increased with the aging, it was consistent with the real situation. By comparing Bref and BL30, the relaxation times of the stress reduction to 50 and $25 \%$ increased with the modification of lignin. Lignin prolonged the time that shear stress declines to a certain level, which had a negative effect on the relaxation properties. The results were consistent with the analysis of the residual stress ratio. However, bio-oil significantly declined the relaxation time and improved the situation. The lignin modified bitumen with bio-oil even needed less time than the neat bitumen, it showed improved relaxation performance.

\subsection{Bending Beam Rheometer Test}

Bending Beam Rheometer tests give indications to determine the ability to resist low temperature cracking of bitumen. The stiffness modulus $(s)$ and creep rate $(m)$ of aged samples at $60 \mathrm{~s}$ were recorded and analyzed to evaluate the low temperature properties and shown in Fig.14. The creep stiffness characterizes the toughness, resistance to deformation, and possibility of cracking at low temperatures. The creep rate indicates the ability to diffuse the stress accumulated and the relaxation rheological property of binders (Wang et al. 2011; Yu et al. 2021). The specification requires that creep stiffness must be less than $300 \mathrm{MPa}$ and m-value must be greater than 0.3. Fig.14 showed that the creep stiffness increases and $m$-value decreases with temperature decline, it revealed that the thermal cracking resistance and relaxation properties decrease. This is mainly due to the gradual increase in the stiffness and brittleness of bitumen as the temperature decreases.

The addition of lignin enhanced the creep stiffness and reduced the m-value by comparing the sample Bref and BL30, it implied that the lignin modified bitumen is more vulnerable to thermal cracking than neat bitumen. However, as the content of bio-oil increases, this phenomenon is alleviated and improved. The higher the bio-oil dosage, the lower $S$ and the higher $m$ were observed by comparison with lignin modified bitumen, BL30. It showed that bio-oil as a rejuvenator or softener eliminates the hardening effect of lignin on bitumen, and 
increases the light component of lignin-modified asphalt. It significantly improves the resistance to low-temperature cracking and relaxation of lignin modified bitumen. This is consistent with the results and conclusions obtained from the DSR tests.

\subsection{Summary of Properties}

In this study, the different properties of lignin-oil-bitumen systems were evaluated through a series of tests. The FTIR test evaluated the aging performance of materials by analyzing chemical functional groups. The workability of the material was represented by the viscosity measured by the viscometer. DSR tests were employed to assess the mechanical performance. High-temperature stability, fatigue life, resistance to cracking, and relaxation property were measured by MSCR, LAS, G-R parameter, BBR, and Relaxation test respectively. To obtain the optimal dosage of bio-oil, different properties were analyzed systematically as different dimensions and perspectives. The various studied materials in the lignin-oil-bitumen system were sorted based on their performance characteristics. The larger the value, the improved the properties, as illustrated in Fig.15. Lignin can greatly improve the anti-aging and hightemperature properties of bitumen, while the bio-oil had a significant improvement effect in other properties. For BL30 and BL30+4\% Oil, some of the properties were excellent but meanwhile had obvious drawbacks. While the lignin modified bitumen with 3\% bio-oil had no shortcomings and an all-around improvement effect. Therefore, $3 \%$ was recommended as the optimal content.

\section{Conclusions}

Lignin significantly increased the modulus and high-temperature stability of bitumen causing in parallel with binders prone to thermal and fatigue cracking. The research presented in this study had shown the preliminary results on using a bio-oil in lignin modified bituminous binders to ameliorate the potential durability shortcomings. The key findings of this research are as follows:

1. FTIR tests demonstrated lignin has a remarkable anti-aging effect, bio-oil slightly deteriorates the anti-aging effect. lignin dramatically enhanced the viscosity, while adding bio-oil can reduce the viscosity of lignin-modified bitumen to improve workability.

2. The recoverability and high temperature stability of bitumen were improved by lignin. 
With the increase of bio-oil, it gradually reduced the rutting resistance, but still better than that of neat bitumen.

3. It was found that the addition of lignin reduced the fatigue life at 2.5 and $5.0 \%$ of stress levels, and higher bio-oil content could better improve the fatigue performance of lignin-modified bitumen.

4. The thermal cracking behavior was demonstrated by the G-R parameter, R-value, and BBR tests. Although the lignin modified bitumen was prone to cracking, bio-oil strengthened the overall crack resistance.

5. The relaxation test revealed that lignin increases the residual stress ratio and relaxation time, thus reducing the relaxation performance. The negative effects can be eliminated by adding bio-oil.

6. Based on all the significant tests done in this study, the recommended dosage of biooil in lignin modified bitumen is $3 \%$, as this content showed a significant improvement in the intermediate and low temperature performances without adversely affecting the high-temperature properties.

To sum up, bio-oil significantly enhanced the low-intermediate temperature properties of lignin modified binder, and especially the fatigue and thermal cracking resistance. Meanwhile, there is no adverse effect on the improvement impacts of lignin on the neat binder about the high-temperature performance, such as modulus, recovery ability, rutting resistance, and temperature stability. The use of bio-oil in combination with lignin can greatly increase the content of lignin in bitumen without losing the mechanical properties of binders, hence lignin is indeed feasible to partially replace bitumen. This paper focused on the binder properties. Characteristics at the mixture level, such as adhesion or raveling performance of bio-asphalt materials, will be studied in the future. In addition, the related chemical properties and molecular simulations will also be further studied in the future.

\section{Data Availability}

b. All data, model, and code generated or used during the study appear in the submitted article.

\section{Acknowledgments}

The first author would like to acknowledge the scholarship from the China Scholarship Council (No.201906560029). Special thanks to Nedvang and Boskalis for the cooperation. 


\section{References}

AASHTO T 315-19. Standard Method of Test for Determining the Rheological Properties of Asphalt Binder Using a Dynamic Shear Rheometer (DSR). AASHTO: Washington, DC, USA, 2019.

AASHTO TP 101-14. Standard Method of Test for Estimating Damage Tolerance of Asphalt Binders Using the Linear Amplitude Sweep. AASHTO: Washington, DC, USA, 2014.

Airey, G.D. Use of Black Diagrams to identify Inconsistencies in Rheological Data. Road Mater. Pavement Des. 2002, 3, 403-424.

Anderson, M.; Le Hir, Y.M.; Marasteanu, M.O.; Planche, J.-P.; Martin, D.; Gauthier, G. Evaluation of Fatigue Criteria for Asphalt Binders. Transp. Res. Rec. 2001, 1766, 48-56.

Apostolidis P. Experimental and Numerical Investigation of Induction Heating in Asphalt Mixes. Delft University of Technology, M.Sc. Thesis, 2015.

Arafat, S., N. Kumar, N.M. Wasiuddin, E.O. Owhe, J.G. Lynam. Sustainable Lignin to Enhance Asphalt Binder Oxidative Aging Properties and Mix Properties. Journal of Cleaner Production 217, 2019, pp. 456-468.

ASTM International. Standard Test. Method for Multiple Stress Creep and Recovery (MSCR) of Asphalt Binder Using a Dynamic Shear Rheometer: ASTM D 7405-15; ASTM International: West Conshohocken, PA, USA, 2015.

Batista, K.B., R.P.L. Padilha, T.O. Castro, C.F.S.C. Silva, M.F.A.S. Araujo, L.F.M. Leite, V.M.D. Pasa, V.F.C Lins. High-temperature, Low-temperature and Weathering Aging Performance of Lignin Modified Asphalt Binders. Industrial Crops \& Products 111, 2018, pp. 107-116.

Braunauer S., Emmett P.H. \& Teller E. Adsorption of Gases in Multimolecular Layers. Journal of the American Chemical Society, Vol. 60, No. 2, pp 309-319, 1938.

Bruijnincx, P., G.-J. Gruter, A. Westenbroek, E. Engelen-Smeets. Lignin Valorisation: The Importance of a Full Value Chain Approach. 2016.

Dhasmana, H., Ozer, H., Al-Qadi, I. L., Zhang, Y., Schideman, L., Sharma, B. K., ... \& Zhang, P. (2015). Rheological and chemical characterization of biobinders from different biomass resources. Transportation Research Record, 2505(1), 121-129.

Ding, L., Wang, X., Zhang, M., et al. Morphology and properties changes of virgin and aged asphalt after fusion. Construction and Building Materials, 291(2021)123284.

Fini, E. H., Kalberer, E. W., Shahbazi, A., Basti, M., You, Z., \& Ozer, H., et al. Chemical characterization of biobinder from swine manure: sustainable modifier for asphalt binder, J. Mater. Civ. Eng. 23 (11) (2011) 1506-1513.

Gao, J., Wang, H., Liu, C., Ge, D., You, Z., \& Yu, M. (2020). High-temperature rheological behavior and fatigue performance of lignin modified asphalt binder. Construction and Building Materials, 230, 117063.

Girimath, S., \& Singh, D. (2019). Effects of bio-oil on performance characteristics of base and recycled asphalt pavement binders. Construction and Building Materials, 227, 116684.

Golalipour, A. Investigation of the Effect of Oil Modification on Critical Characteristics of Asphalt Binders. University of Wisconsin-Madison, 2013.

Gosselink, R.J.A. Lignin as a Renewable Aromatic Resource for the Chemical Industry. PhD Thesis, Wageningen University, 2011.

Haghshenas, H. F., Rea, R., Reinke, G., \& Haghshenas, D. F. (2020). Chemical Characterization 
of Recycling Agents. Journal of Materials in Civil Engineering, 32(5), 06020005.

Haghshenas, H. F., Fini, E., Rea, R., \& Khodaii, A. (2021). Increasing the efficacy of recycling agents with simultaneous addition of zinc diethyldithiocarbamate as an antioxidant. Construction and Building Materials, 271, 121892.

Hintz, C., H. Bahia. Simplification of Linear Amplitude Sweep Test and Specification Parameter. In Transportation Research Record, No. 2370, National Research Council, Washington, D.C., 2013, pp. 10-16.

Jing, R. Ageing of Bituminous Materials: Experimental and Numerical Characterization. Ph.D. Thesis, Delft University of Technology, Delft, The Netherlands, 2019.

Kataware A V, Singh D. Dynamic mechanical analysis of crumb rubber modified asphalt binder containing warm mix additives. International Journal of Pavement Engineering, 2019, 20(9): 1044-1054.

King, G., M. Anderson, D. Hanson, P. Blankenship. Using Black Space Diagrams to Predict Age-induced Cracking. In 7th RILEM International Conference on Cracking in Pavements, Springer, Dordrecht, 2012, pp. 453-463.

Lamontagne, J., Dumas, P., \& Mouillet, V. (2001). Comparison by fourier transform infrared (FTIR) spectroscopy of different ageing techniques: application to road bitumens. Fuel, 80(4), 483-488.

Lei, Z. , Bahia, H. , Tan, Y. Q. , \& Ling, C. . (2017). Effects of refined waste and bio-based oil modifiers on rheological properties of asphalt binders. Construction \& Building Materials, 148(sep.1), 504-511.

Li, Y., Moraes, R., Lyngdal, E., Bahia, H. Effect of Polymer and Oil Modification on the Aging Susceptibility of Asphalt Binders. Transportation Research Record, No. 2574, National Research Council, Washington, D.C., 2016, pp. 28-37.

Ma, F., Li, X., Fu, Z. Research progress in road performance of bio-modified asphalt rubber and the mixture, J. Wuhan Univ. Technol. 37 (2) (2015) 55-62.

Mensching, D.J., Rowe, G.M.; Daniel, J.S.; Bennert, T. Exploring Low-temperature Performance in Black Space. Road Mater. Pavement Des. 2015, 16, 230-253.

Metwally, M. Development of non-petroleum binders derived from fast pyrolysis bio-oils for use in flexible pavement, Dissert. Theses - Gradworks, 2010.

Mills-Beale, J., You, Z., Fini, E., Zada, B., Lee, C. H., \& Yap, Y. K. (2014). Aging influence on rheology properties of petroleum-based asphalt modified with biobinder. Journal of Materials in Civil Engineering, 26(2), 358-366.

Mogawer, W. S., Fini, E. H., Austerman, A. J., Booshehrian, A., \& Zada, B. (2016). Performance characteristics of high reclaimed asphalt pavement containing bio-modifier. Road Materials and Pavement Design, 17(3), 753-767.

Moghaddam, T. B., \& Baaj, H. (2016). The use of rejuvenating agents in production of recycled hot mix asphalt: a systematic review. Construction and Building Materials, 114, 805-816.

Moraes, R. Investigation of Mineral Filler Effects on the Aging Process of Asphalt Mastics. University of Wisconsin-Madison, 2014.

Norgbey, E., Huang, J., Hirsch, V., Liu, W., Wang, M., Ripke, O., Li, Y., Takyi Annan, G. e., Ewusi-Mensah, D., Wang, X., Treib, G., Rink, A., Nwankwegu, A., Opoku, P. \& Nkrumah, P. Unravelling the efficient use of waste lignin as a bitumen modifier for sustainable roads. Construction and Building Materials, 2020, 230, 116957. 
Osmari, P. H., Leite, L. F. M., Aragão, F. T. S., Cravo, M. C. C., Dantas, L. N., \& Macedo, T. F. (2019). Cracking resistance evaluation of asphalt binders subjected to different laboratory and field aging conditions. Road Materials and Pavement Design, 20(sup2), S663-S677.

Peralta, J., Raouf, M. A., Tang, S., \& Williams, R. C. (2012). Bio-renewable asphalt modifiers and asphalt substitutes. In Sustainable bioenergy and bioproducts (pp. 89-115). Springer, London.

Perez, I.P., A.M. Rodriguez Pasandin, J.C. Pais, P.A.A. Pereira. Use of Lignin Biopolymer from Industrial Waste as Bitumen Extender for Asphalt Mixtures. Journal of Cleaner Production 220, 2019, pp. 87-98.

Raouf, M. A., \& Williams, C. R. (2010). General rheological properties of fractionated switchgrass bio-oil as a pavement material. Road Materials and Pavement Design, 11 (sup1), 325-353.

Ren, S., Liu, X., Zhang, Y., Lin, P., \& J Xu. (2021). Multi-scale characterization of lignin modified bitumen using experimental and molecular dynamics simulation methods. Construction and Building Materials, 287(4), 123058.

Rowe, G., \& Sharrock, M. (2016). Cracking of asphalt pavements and the development of specifications with rheological measurements. E\&E Congress 2016, 6th Eurasphalt \& Eurobitume Congress, Prague, Czech Republic.

Ruan, Y., R. R. Davison, and C. J. Glover. Oxidation and Viscosity Hardening of PolymerModified Asphalts. Energy and Fuels, Vol. 17, 2003, pp. 991-998.

Su, N., Xiao, F., Wang, J., Cong, L. \& Amirkhanian, S. Productions and applications of bioasphalts-A review. Construction and Building Materials, 2018, 183, 578-591.

Sundestrom, D.W., H.E. Klel, T.H. Daubenspeck. Use of Byproduct Lignins as Extenders in Asphalt. Ind. Eng. Chem. Prod. Res. Dev. 22, 1983, pp. 496-500.

Van Vliet, D., T. Slaghek, C. Giezen, I. Haaksman. Lignin as a Green Alternative for Bitumen. In Proceedings of the 6th Euroasphalt \& Eurobitume Congress, Prague, Czech Republic, 2016.

Wang, X., Ji, G., Zhang, Y., Guo, Y., \& Zhao, J. (2021). Research on high- and low-temperature characteristics of bitumen blended with waste eggshell powder. Materials, 14(8), 2020.

Wen, H., Bhusal, S., \& Wen, B. Laboratory evaluation of waste cooking oil-based bioasphalt as an alternative binder for hot mix asphalt, J. Mater. Civil Eng. 25 (10) (2012) 1432-1437.

$\mathrm{Xu}, \mathrm{G}$., H. Wang, H. Zhu. Rheological Properties and Anti-aging Performance of Asphalt Binder modified with Wood Lignin. Construction and Building Materials 151, 2017, pp. 801-808.

Xu, S., Liu, X., Tabaković, A., Lin, P., Zhang, Y., \& Nahar, S., et al. (2021). The role of rejuvenators in embedded damage healing for asphalt pavement. Materials \& Design (1), 109564.

Xu, Y., You, Z., Dai, Q., \& Mills-Beale, J. (2014). Mechanical performance of asphalt mixtures modified by bio-oils derived from waste wood resources. Construction \& Building Materials, 51(Jan.), 424-431.

Yu, J., Vaidya, M., Su, G., Adhikari, S., \& Shekhovtsova, S. (2021). Experimental study of soda lignin powder as an asphalt modifier for a sustainable pavement material. Construction and Building Materials, 298(3), 123884. 
Zhang, Y.; Liu, X.; Apostolidis, P.; Gard, W.; van de Ven, M.; Erkens, S.; Jing, R. Chemical and Rheological Evaluation of Aged Lignin-Modified Bitumen. Materials, 2019, 12, 4176.

Zhang, Y.; Liu, X.; Apostolidis, P.; Jing, R.; Erkens, S.; Poeran, N.; Skarpas, A. Evaluation of Organosolv Lignin as an Oxidation Inhibitor in Bitumen. Molecules, 2020, 25, 2455.

Table 1 The primary performance parameters of materials.

\begin{tabular}{|c|c|c|}
\hline Materials & Properties & Value \\
\hline \multirow{9}{*}{ Bitumen } & Penetration $\left(25^{\circ} \mathrm{C}, 0.1-\mathrm{mm}\right)$ & 78.5 \\
\hline & Softening point $\left({ }^{\circ} \mathrm{C}\right)$ & 47.5 \\
\hline & Ductility $\left(5 \mathrm{~cm} / \mathrm{mm}, 15^{\circ} \mathrm{C}, \mathrm{cm}\right)$ & $>100$ \\
\hline & Flash Point & 280 \\
\hline & Wax Content (\%) & 1.6 \\
\hline & Specific Gravity $\left(25^{\circ} \mathrm{C}\right)$ & 1.032 \\
\hline & Rotational Viscosity $\left(135^{\circ} \mathrm{C}, \mathrm{Pa} \cdot \mathrm{s}\right)(<3.0)$ & 0.63 \\
\hline & $\mathrm{G}^{*} / \sin \delta\left(64^{\circ} \mathrm{C}\right.$ for virgin binder, $\left.\mathrm{kPa}\right)(>1.0)$ & 1.304 \\
\hline & $\mathrm{G}^{*} / \sin \delta\left(64^{\circ} \mathrm{C}\right.$ for RTFO residue, $\left.\mathrm{kPa}\right)(>2.2)$ & 2.649 \\
\hline \multirow{5}{*}{$\begin{array}{l}\text { Organosolv } \\
\text { Lignin }\end{array}$} & Purity & $>88 \%$ \\
\hline & Density (Fresh, $\mathrm{g} / \mathrm{cm}^{3}$ ) & 1.3774 \\
\hline & Specific surface area $\left(\right.$ Fresh, $\left.\mathrm{m}^{2} / \mathrm{g}\right)$ & 147.0593 \\
\hline & Density (Aged, $\mathrm{g} / \mathrm{cm}^{3}$ ) & 1.5029 \\
\hline & Specific surface area $\left(\right.$ Aged, $\left.\mathrm{m}^{2} / \mathrm{g}\right)$ & 65.0475 \\
\hline \multirow{5}{*}{ Bio-oil } & Density $\left(\mathrm{g} / \mathrm{cm}^{3}\right)$ & 0.928 \\
\hline & Viscosity $\left(20^{\circ} \mathrm{C}, \mathrm{Pa} \cdot \mathrm{s}\right)$ & 0.115 \\
\hline & Saturated fatty acid (\%) & 7 \\
\hline & Monounsaturated fatty acid (\%) & 61 \\
\hline & Polyunsaturated fatty acid (\%) & 32 \\
\hline
\end{tabular}


Table 2 Typical functional groups of bitumen in FTIR spectra.

\begin{tabular}{cc}
\hline Wavenumber $\left(\mathrm{cm}^{-1}\right)$ & Functional Groups \\
\hline $2990-2880$ & Stretching aromatic \\
$2880-2820$ & Stretching symmetric \\
$1760-1660$ & Oxygenated functional group \\
$1670-1535$ & Aromatic structures \\
$1525-1395$ & Aliphatic structures \\
$1390-1350$ & Oxyched aliphatic structures \\
$1047-995$ & Out of singlet \\
$912-838$ & Out of adjacent \\
$838-783$ & Out of adjacent \\
$783-734$ & Long chains \\
$734-710$ &
\end{tabular}

Table 3 The rutting and fatigue parameters fitting functions for studied binders.

\begin{tabular}{|c|c|c|c|c|}
\hline \multirow{2}{*}{ Binders } & \multicolumn{4}{|c|}{$\mathrm{G}^{*} / \sin \delta$} \\
\hline & \multicolumn{2}{|l|}{ Fresh } & \multicolumn{2}{|l|}{ Aged } \\
\hline Bref & $y=1.587 \times 10^{8} e^{-0.184 x}$ & $R^{2}=0.98$ & $y=3.844 \times 10^{8} e^{-0.153 x}$ & $R^{2}=0.98$ \\
\hline BL30 & $y=2.884 \times 10^{8} e^{-0.176 x}$ & $R^{2}=0.97$ & $y=4.784 \times 10^{8} e^{-0.144 x}$ & $R^{2}=0.97$ \\
\hline BL30+2\% Oil & $y=1.479 \times 10^{8} e^{-0.178 x}$ & $R^{2}=0.98$ & $y=2.903 \times 10^{8} e^{-0.145 x}$ & $R^{2}=0.98$ \\
\hline BL30+3\% Oil & $y=9.773 \times 10^{7} e^{-0.176 x}$ & $R^{2}=0.98$ & $y=2.190 \times 10^{8} e^{-0.146 x}$ & $R^{2}=0.98$ \\
\hline BL30+4\% Oil & $y=8.190 \times 10^{7} e^{-0.175 x}$ & $R^{2}=0.99$ & $y=1.426 \times 10^{8} e^{-0.145 x}$ & $R^{2}=0.98$ \\
\hline \multirow{2}{*}{ Binders } & \multicolumn{4}{|c|}{$\mathrm{G}^{*} \sin \delta$} \\
\hline & \multicolumn{2}{|l|}{ Fresh } & \multicolumn{2}{|l|}{ Aged } \\
\hline Bref & $y=4.577 \times 10^{7} e^{-0.157 x}$ & $R^{2}=0.92$ & $y=5.803 \times 10^{7} e^{-0.118 x}$ & $R^{2}=0.92$ \\
\hline BL30 & $y=7.679 \times 10^{7} e^{-0.148 x}$ & $R^{2}=0.90$ & $y=6.823 \times 10^{7} e^{-0.109 x}$ & $R^{2}=0.92$ \\
\hline BL30+2\% Oil & $y=5.390 \times 10^{7} e^{-0.156 x}$ & $R^{2}=0.93$ & $y=5.186 \times 10^{7} e^{-0.114 x}$ & $R^{2}=0.94$ \\
\hline BL30+3\% Oil & $y=3.870 \times 10^{7} e^{-0.156 x}$ & $R^{2}=0.94$ & $y=4.378 \times 10^{7} e^{-0.117 x}$ & $R^{2}=0.95$ \\
\hline BL30+4\% Oil & $y=2.910 \times 10^{7} e^{-0.159 x}$ & $R^{2}=0.96$ & $y=3.328 \times 10^{7} e^{-0.118 x}$ & $R^{2}=0.96$ \\
\hline
\end{tabular}

